\title{
Efficacy of McConnell's Medial Patellar Taping Application for Pain Management and Walking Velocity of Osteoarthritis Patients
}

\author{
Wahju Hidajati ${ }^{1}$, Angela BM Tulaar ${ }^{1}$, Yoga Iwanoff Kasjmir $^{2}$, Sumariyono ${ }^{2}$, Surjanto M.A ${ }^{3}$ \\ 1 Department of Physical Medicine and Rehabilitation, Faculty of Medicine - University of \\ Indonesia, Jakarta \\ 2 Department of Internal Medicine, Rheumatology Division, Faculty of Medicine - University of \\ Indonesia, Jakarta \\ 3 Medical Research Unit, Faculty of Medicine - University of Indonesia, Jakarta
}

\begin{abstract}
Objectives: to evaluate the efficacy of medial patellar taping in addition to exercise for pain relief and 15 meters walking time, and to find any correlation between the pain improvement and functional outcome.

Methods: This study was a randomized controlled trial of knee patellar taping in combination with the isometric and stretching exercise in comparison to taping free- exercise. The inclusion criteria includes knee osteoarthritis patients with VAS score ranges four to eight of each knee, with or without tolerable pain on the other knee. The treatment group received knee tapping and isometric and stretching exercise of the quadriceps, iliotibial band, hamstring and gastrocnemius muscles. Both treatment and control group were assessed for about three weeks (day 1/week 0, day 2, day 28/week 4, and day 49/week 7). A visual analogue scale (VAS) was used to assess knee pain severity whereas $15 \mathrm{~m}$ walking time assessed to measure functional gait performance. On day 2, both measurements were done for study group only, with assumption the result would be the same with 1 day exercise only. A Lequesne index measured functional outcome.

Results: There were 24 participants, twelve patients were in the tapped group while the remaining twelve were in the control group. Significant pain differences were visible during the treatment period at day 1, day 2 and at the beginning of week 7 . At day 2 and week 4, the study group showed significant pain reduction in comparison to the control group $(\mathrm{p}<0.007)$.

The walking time also showed significant improvement in the study group at day $2(p<0.000)$ but there were no significant difference at week 4 and week 7 . At week 7 , the study group experienced pain $(p<0.037)$ and outcome improvement significantly. In addition, for about $75 \%$ of them had none to moderate disability post intervention. Meanwhile, from the total of eight patients in the control group who had severe to very severe disability, four of them had moderate $(50 \%)$ and the rest had mild disability $(50 \%)$. There was significant correlation between the pain and functional outcome on day two.

Conclusions: Medial Patellar Taping in addition to isometric and stretching exercise of quadriceps, iliotibial band, hamstrings and gastrocnemius muscles showed significant improvement of disability superior to the untapped group. Benefits of Medial Patellar Taping remained three weeks after removal.
\end{abstract}

Keywords: Osteoarthritis, Knee Pain Severity, exercise, Medial Patellar Taping, Visual Analogue Scale, 15 Meter Walking Time, Functional Gait Performance, Lequesne Index.

Received in March 2013 and accepted for published in April 2013.

Correspondence address: Wahju Hidajati, Rehabilitation Medicine Department, Pantai Indah Kapuk Hospital, Pantai Indah Utara No.3, Kapuk Muara - Penjaringan, Jakarta Utara 14460, DKI Jakarta, Indonesia. Email: elizawahju@gmail.com

\section{INTRODUCTION}

Osteoarthritis is the most common joint disease encountered, and the knee joint is commonly affected. ${ }^{1}$ Osteoarthritis increases with age, and 
sex-specific differences are evident. Before 50 years of age, the prevalence of osteoarthritis in most joints is higher in men. After about age 50 years, women are more often affected. ${ }^{2}$ There is no known cure for osteoarthritis, and the goal of contemporary management of the patient with osteoarthritis remains control of pain and improvement in function and health-related quality of life with avoidance, if possible, of therapeutic toxicity. The potential of treatments ranging from newly approved oral medications to neutriceuticals, patient education interventions, and surgery. ${ }^{3}$ Simple, inexpensive treatments that increase the range of options for patients with the disease are warranted. Knee taping is believed to relieve pain. It has been one of strategies that recommended by the American College of Rheumatology for the management of knee osteoarthritis. ${ }^{4}$ This study has not been done for the Indonesians.
In Indonesia, osteoarthritis is the most common rheumatic disease. At rheumatology division of Cipto Mangunkusumo Hospital there was $36.5 \%$ new rheumatic outpatients on the year of $2000 .^{5}$ There are several risk factors involved in the development of osteoarthritis (figure 1). Any intervention with significant effect on one or more of these factors can inhibit or delay the development of osteoarthritis. Knee osteoarthritis accounts for the highest percentage of disability in walking, stair climbing and housekeeping. ${ }^{6}$ Altered knee loading during weight-bearing may result in pain due to interosseous pressure, effusion and ischemia, which would interfere with walking performance. Compared to healthy adults, people with knee osteoarthritis walk more slowly due to shorter stride length or decrease cadence and with decreased sagittal plane knee motion. ${ }^{1}$

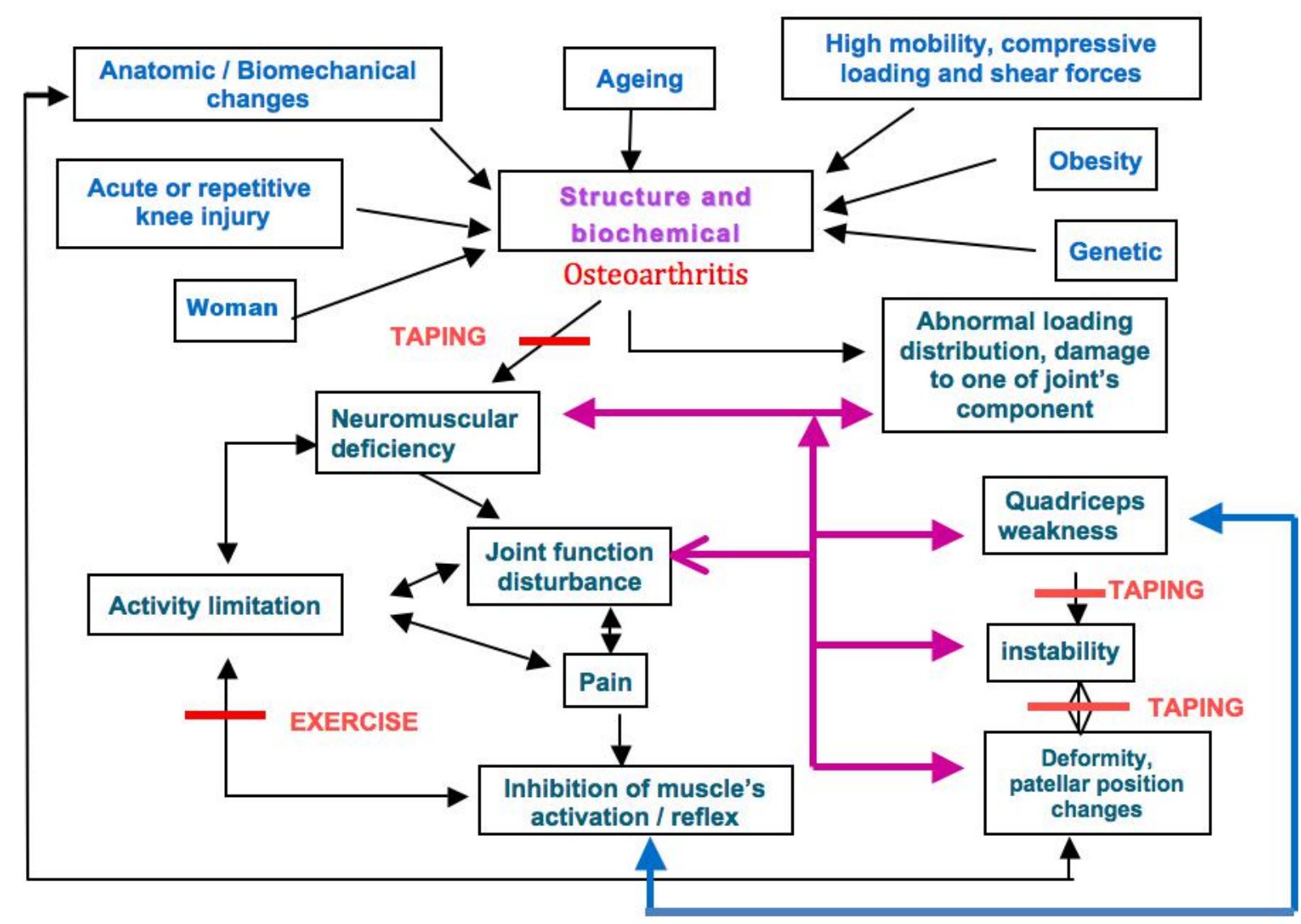

Figure 1. Risk Factors and Mechanism of Knee Osteoarthritis 
Knee is a joint that has to bear a very heavy burden due to locomotion and so ready to resent the load to the other bones. ${ }^{7}$ Whilst, the bony configuration contributes little to the stability and integrity of the joint. Strength is dependent upon the integrity of the muscles and secondarily upon the ligaments. ${ }^{8}{ }^{8}$ Pain and joint stiffness in osteoarthritis leads to activity limitation that in turn, leads to quadriceps disuse atrophy, loss in $30 \%$ of muscles mass in a week and decreased in 5\% of power per day. All these factors lead to periarticular weakness and have a role in worsening of osteoarthritis. ${ }^{10}$

Patellofemoral joint is usually affected as part of osteoarthritis of the knee. The patella tracks within the femoral groove as the knee moves. The quadriceps muscle helps control the patella so it stays within the groove. If part of the quadriceps is weak for any reason, a muscle imbalance can occur. When this happens, the pull of the quadriceps may cause the patella to pull more to one side than the other. This in turn causes more pressure on the articular cartilage on one side than the other. In time, this pressure can damage the articular cartilage. A similar problem can happen when the timing of the quadriceps is off. People with patellofemoral problems sometimes have problems in the timing between the Vastus Medialis Oblique and the Vastus Lateralis. The Vastus Lateralis contracts first, before the Vastus Medialis Oblique. This tends to pull the patella toward the outside of edge of the knee, resulting abnormal pressure on the patellar articular surface. ${ }^{9}$ Removing pain leads to worsening of the situation, i.e. lesser muscle activity to absorb shock during walking. If the knee is very malaligned or lax, the line of action for quadriceps is altered so an increase in quadriceps strength may thus lead to worsening of osteoarthritis. In their studies, Barret and Marks indicate that patients with knee osteoarthritis have poor proprioception compared to healthy subjects. However, according to Sharma this poor proprioception is not isolated to the affected knee joint but also the contralateral joint, otherwise diagnosed as healthy. ${ }^{6}$

Patellofemoral Pain Syndrome is a common condition presenting to physiotherapist and orthopaedic surgeons. Despite its prevalence, the aetiology, pathogenesis and recommended treatment remain unclear. The success rate of treatment regimens for this condition has been very poor and in the long-term, the condition frequently recurs. In the past the only available options were surgery or curtailing physical activity. ${ }^{11}$

Patellar taping has been a choice of intervention for Patellofemoral Pain Syndrome (PFPS). McConnell introduced a program that incorporates patellar taping techniques to improve patellar tracking within the patellofemoral groove, allowing patients to engage in pain-free physical therapy exercises. ${ }^{12}$ Taping technique provides support and protection while allowing functional movement. Providing support to an injured body part may allow early return to activity, yet control undesirable movement that may impede the healing process. ${ }^{13}$ Even if osteoarthritis cannot be cured, inactivity can be cured. ${ }^{6}$ For these reasons, some investigators used patellar taping for PFPS. 4,12,14-16

Despite substantial evidence demonstrating tape's immediate pain-relieving effect, it remains unclear how this is achieved. It has been suggested that cutaneous and mechanical effects of tape may enhance sensorimotor variables, such as proprioceptive acuity, quadriceps strength and Vastus Medialis Oblique onset. Several studies demonstrate an immediate, positive effect of tape on relieving pain because of knee osteoarthritis. ${ }^{14}$

Taping the knee is meant as a temporary solution to knee pain and should never replace the exercise that corrects the cause of the pain. Taping often helps to relieve the patient's discomfort and allow him or her to exercise with greater intensity. It's the exercise that provides a lasting benefit. The kneecap is taped every day for 3 weeks. Then the patient is gradually weaned off by taping every other day. The patient should not become dependent on the taping and should only use this procedure for temporary pain relief. Patellar taping reduces pain during exercise while the exercise strengthens the muscles and tendons that stabilize the kneecap. ${ }^{17}$

The aims of this current study were to determine whether:

1. Knee patellar taping give greater improvement of pain severity and functional outcome in addition to exercise in patients with knee osteoarthritis compared with 
exercise only.

2. There were any correlation between improvement of pain severity and functional outcome.

\section{METHODS}

The design of the study was a randomized clinical study comparing isometric and stretching exercise with McConnell's medial patellar taping of affected knee in addition to exercise. The exercises was tailored at strengthened and stretched the muscles of quadriceps, iliotibial band, hamstring and gastrocnemius. Participants, who are all women, with moderate unilateral knee pain, were asked about the study at a rehabilitation medicine department and rheumatology outpatient clinic of Cipto Mangunkusumo hospital. Diagnosis was consistent with the American College of Rheumatology criteria, either based on radiographs or clinical signs and symptoms ${ }^{1,18}$ Radiographic assessments was done on weight-bearing position and skyline view. Ethical approval was given by the University of Indonesia Research Ethic Committee. The plan of the study is set out in figure 2 .

The criteria for inclusion were female aged 50-65 years old; unilateral osteoarthritis with moderate knee pain (VAS 4 - 8), II - IV grade without deformity (with or without analgesic); Q angle $£ 15^{\circ}$ (clinical and radiograph); without past history of fall that hit the knee (a year before); have walking ability without any device; no signs of inflammation, skin irritation and around taping area; and agreed to follow the complete procedure of this study.

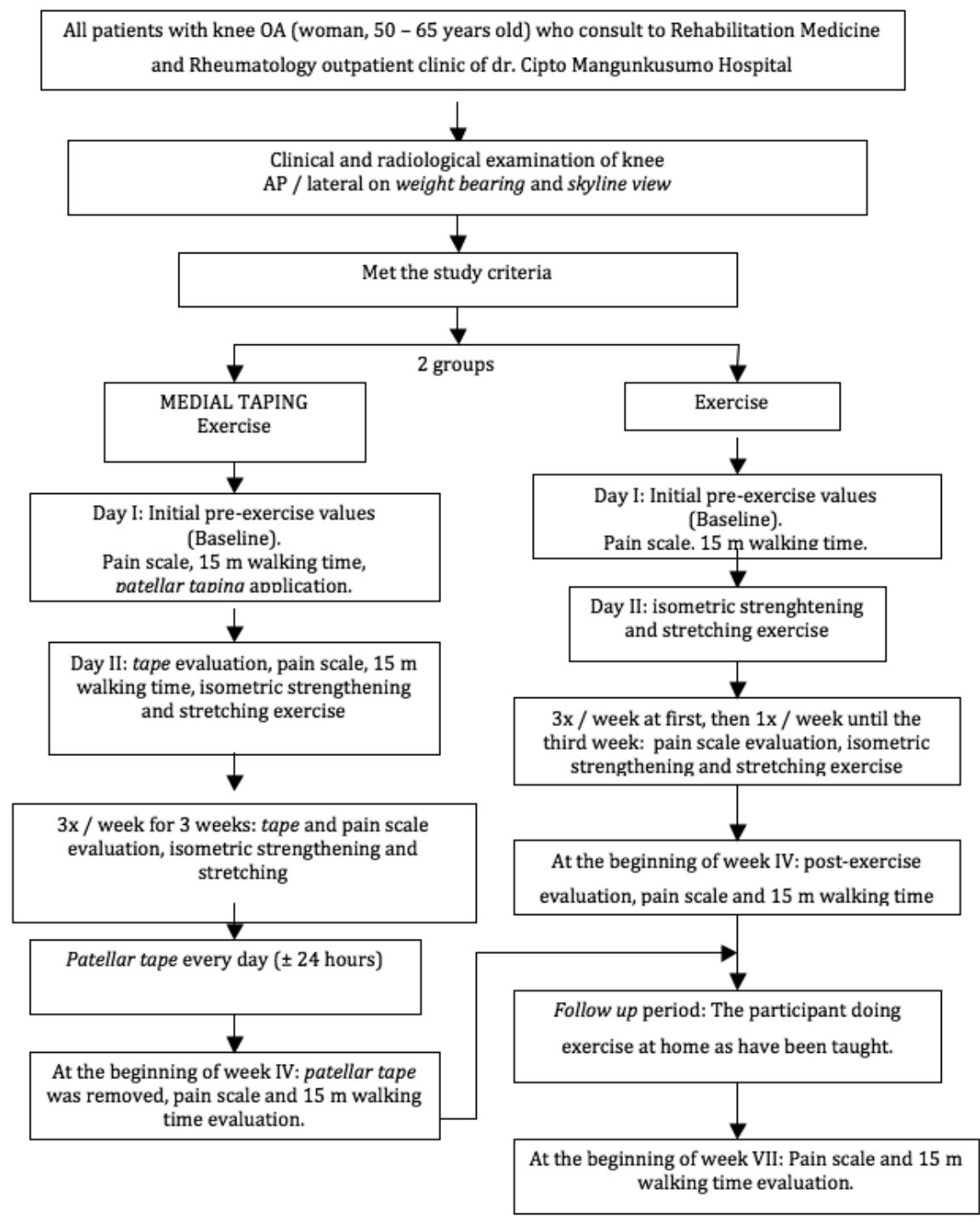

Figure 2. Flow diagram of study plan 
Patients were excluded because of presenting the following clinical signs and symptoms: allergy to tape, medical or other musculoskeletal problems that would affect ability to complete the objective tests, neurological problems (stroke, DM peripheral neuropathy and other cause) and or cognitive deficit, hypertension grade II (according to JNC VII), history of surgery or trauma of knee joint, history of steroid injection in the last month, and history of hyaluronic acid injection in the last 2 weeks.

All participants gave written informed consent. They were assigned by 2 closed envelops to receive either medial patellar taping or no tape. All other interventions between two groups were similar.

\section{Protocol}

The trial comprised a three week intervention period and a three week follow up. Participants were assessed before treatment (baseline), day 2, at the beginning of week 4 (final assessment) and 7 (follow up). Tape application was continued for three weeks and reapplied every day to minimize the risk of skin reaction. Hydrocortisone cream $2.5 \%$ applied when the skin allergic was minimal, excluded when the allergic was severe. The patients were allowed to consume paracetamol $500 \mathrm{mg}$ as analgesics. The total paracetamol consumed were counted for evaluation.

All participants that fulfill the inclusion criteria were allocated into two groups, with patellar tape in one group and without tape in another. The same exercise treatment was given to both groups. Measurement on pain scale and $15 \mathrm{~m}$ walking time of both groups were done on day 1 as baseline data. Tape application was done soon after baseline measurement. The change in pain measured objectively on $10 \mathrm{~cm}$ horizontal visual analogue scale (VAS), numbered in $1 \mathrm{~cm}$ increments. Participants rated the severity of knee pain over day one, day two, beginning of week four and seven. It rated on every day movement and during an aggravating activity. The walking speed measured over a 15-meters walkway. Patients were asked to walk as normally but as quickly as they could to the end of the walkway without a walking aid and barefooted. The time in seconds recorded using a standard stopwatch. The walking time of day two was considered the same as day one for the control group. On day 2, both measurements were done for study group only, with assumption the result would be the same for the control group with 1 day exercise only. The tape was worn continuously and re-applied daily to lessen the allergy risk. The irritated skin because of tape was covered by band-aid. The participants were taught how to apply the tape. Evaluation was done 3 times per week for study group. Control group evaluation was done 3 times per week for the first week and once per week for two weeks after. Assessments were carried out for pain, skin reaction of study group, and consistency in doing exercises (from diary). Participants were recommended to exercise six repetitions per movement, two times per day for 6 weeks period. The used of analgesics (paracetamol $500 \mathrm{mg}$ ), pain scale, tape condition and exercises that were done were written on participant's diary. At the beginning of week 4 the application of taping was stopped and the measurement of pain and $15 \mathrm{~m}$ walking time were taken for both groups.

At the follow up period, both groups were recommended to exercise as has been taught. All participants were asked to come for evaluation at the beginning of week 7. Pain scale and 15 meter walking time were retaken as the final data.

\section{Exercise regimen}

The exercises were tailored at strengthened and stretched the muscles of quadriceps, iliotibial band, hamstrings and gastrocnemius. Participants were recommended to exercise six repetitions per movement, two times per day for 6 weeks period. The exercise that could not be done because of severe pain was recorded in participant's diary.

\section{Taping technique}

Hypoallergenic undertape (Fixomull ${ }^{\mathrm{O}}$ stretch or Hypafix ${ }^{\circ}$ ) $\quad 7,5 \mathrm{~cm}$ wide applied beneath rigid tape with $5 \mathrm{~cm}$ wide (Strappal ${ }^{\circ}$ ) from BSN medical Indonesia. The tape application was based on McConnell's medial patellar gliding technique. Tape was applied soon after baseline measurements. The participants were taught 
how to applied the tape. Tape application was evaluated by investigator 3 times per week. The tape was worn continuously and re-applied daily to lessen the allergy risk. Hydrocortisone cream $2.5 \%$ used on tape area when there were mild skin reaction. When there was severe reaction the participant was excluded.

\section{Outcome measures \\ Primary outcomes}

The primary outcomes of this study were change in pain and $15 \mathrm{~m}$ walking speed.

\section{Secondary outcomes}

The secondary outcomes were patellar position and improvement in Lequesne Index. Patellar position was measured by patellar tilt, patellar glide or any other position. The Lequesne index for knee osteoarthritis is a pathology specific subjective assessment of the patient's pain and disability. It is scored between 0 and 24 points, and can be used to categorize arbitrarily the severity of the patient's disability as mild $/$ moderate $(<8$ points), severe / very severe osteoarthritis ( $\geq 8$ points but $<14$ points) or extremely severe ( $\geq 14$ points). ${ }^{19}$ This index can be used to measure improvement in disability functionally. It measured on day one and at the beginning of week seven (end of the study).

\section{Sample size and statistical analysis.}

A change of $1.75 \mathrm{~cm}$ on the pain visual analogue scale was recommended as the minimum clinically important difference in trials of knee osteoarthritis. ${ }^{4}$ In this study, researchers used $5 \mathrm{~cm}$ on the VAS and 7 seconds on the $15 \mathrm{~m}$ walking time as the minimal clinically important difference for these measures. The level of significance was set at $\mathrm{p}<0.05$. Analyses were performed with SPSS software. Baseline comparability was determined with unpaired $t$ test or Mann Whitney. To determine the correlation between change in pain and $15 \mathrm{~m}$ walking time, we use the Pearson or Spearman tests. For each participant, change in scores from baseline was calculated at week three and six.

\section{RESULTS}

Between June and August 2007, 35 patients with knee osteoarthritis from our rheumatology and rehabilitation medicine outpatient clinic were recruited. Of these, 24 met the selection criteria and were enrolled into our study. Reason for nonparticipation included inability to complete the intervention as allocated (7 persons), moderate to severe allergic reaction to the hypoallergenic undertape (4 persons). Twelve participants were randomized to each two groups. Both groups were comparable at baseline.

\section{Primary outcome measures}

At day 2 and after three weeks, the study group showed a significantly greater pain reduction than the control group $(p<0.007)$. The total paracetamol that consumed were much lower in the study group compared to the control group. The walking time also showed significantly greater reduction in the study group at day 2 ( $\mathrm{p}<0.000)$ but there were no significant difference at three and six weeks. At six weeks, a significantly greater reduction in pain from baseline was evident in the study group ( $p<$ 0.037). This indicates a prolonged effect of the tape three weeks after stopping the treatment.

\section{Secondary outcome measures}

Most of the participant had lateral patellar glide and tilt (figure 3 ). The study group experienced a significantly greater reduction in pain and disability on Lequesne index than the control group. The pain reduction was experienced by the participants with patellar glide and tilt or patellar glide only. 
Table 1. Characteristics of Participants

\begin{tabular}{|c|c|c|c|}
\hline Characteristics & & Number & $\%$ \\
\hline \multirow[t]{5}{*}{ Age classification (years) } & $40-44$ & 1 & 4,17 \\
\hline & $45-49$ & 1 & 4,17 \\
\hline & $50-54$ & 6 & 25,00 \\
\hline & $55-59$ & 9 & 37,50 \\
\hline & $60-65$ & 7 & 29,17 \\
\hline \multirow[t]{4}{*}{ BMI classification (kgs/m2) } & (underweight) & 0 & 0 \\
\hline & 18,5-22,9 (normal) & 5 & 20,83 \\
\hline & 23-24,9 (overweight) & 3 & 12,50 \\
\hline & $\geq 25 \quad$ (obese ) & 16 & 66,67 \\
\hline \multirow[t]{5}{*}{ Education } & Never & 1 & 4,17 \\
\hline & SD & 2 & 8,33 \\
\hline & Junior High School & 1 & 4,17 \\
\hline & Senior High School & 8 & 33,33 \\
\hline & University and Academy & 12 & 50 \\
\hline \multirow[t]{5}{*}{ Occupation } & Housewife & 12 & 50 \\
\hline & Employee & 2 & 8,33 \\
\hline & Nurse & 5 & 20,83 \\
\hline & Teacher & 3 & 12,50 \\
\hline & Other & 2 & 8,33 \\
\hline \multirow[t]{3}{*}{ Degree of knee osteoarthritis } & II & 2 & 8,33 \\
\hline & III & 21 & 87,50 \\
\hline & IV & 1 & 4,17 \\
\hline \multirow[t]{3}{*}{ Patellar position } & Lateral patellar glide only & 4 & 16,67 \\
\hline & Lateral patellar tilt only & 0 & 0 \\
\hline & Lateral patellar glide $\&$ tilt & 20 & 83,33 \\
\hline \multirow[t]{3}{*}{ Exercise } & Never & 10 & 41,67 \\
\hline & Yes, not regularly & 3 & 12,50 \\
\hline & Regularly & 11 & 45,83 \\
\hline \multirow[t]{2}{*}{ Exercise Intensity } & Light & 4 & 28,57 \\
\hline & Moderate & 10 & 71,43 \\
\hline \multirow[t]{2}{*}{ Exercise Frequency } & $<3 \mathrm{x}$ a week & 8 & 57,14 \\
\hline & $\geq 3 \mathrm{x}$ a week & 6 & 42,86 \\
\hline
\end{tabular}

Figure 3. Distribution of Patellar Position.

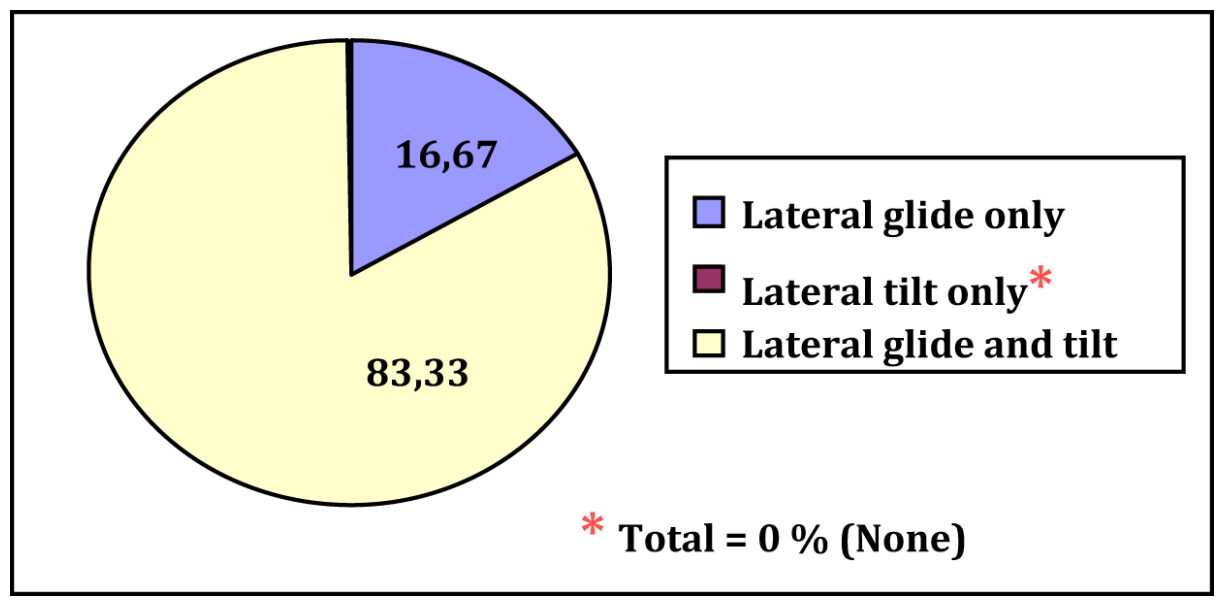


Figure 4. Pain Level Changes of Taping and Intervention Groups

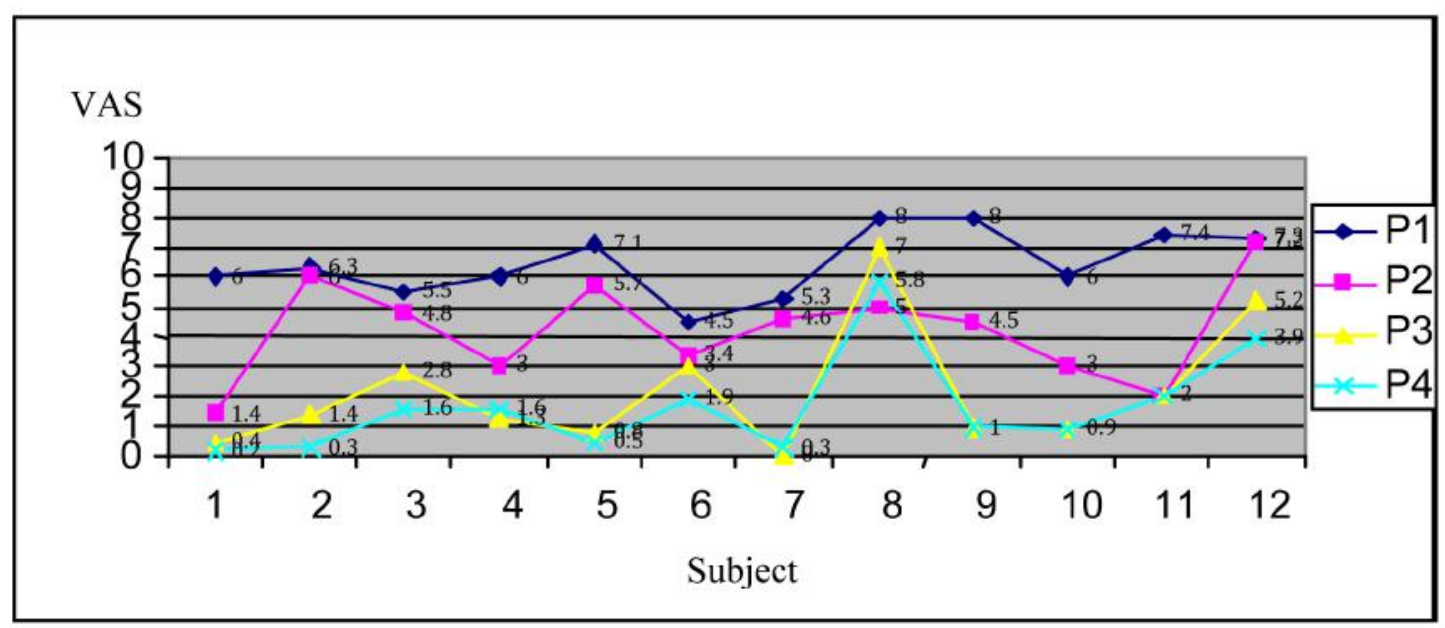

P1 = VAS day 1;

P3 = VAS at the beginning of week 4
P2 = VAS day 2

P4 = VAS at the beginning of week 7

Figure 5. Pain Level Changes in the Exercise group.

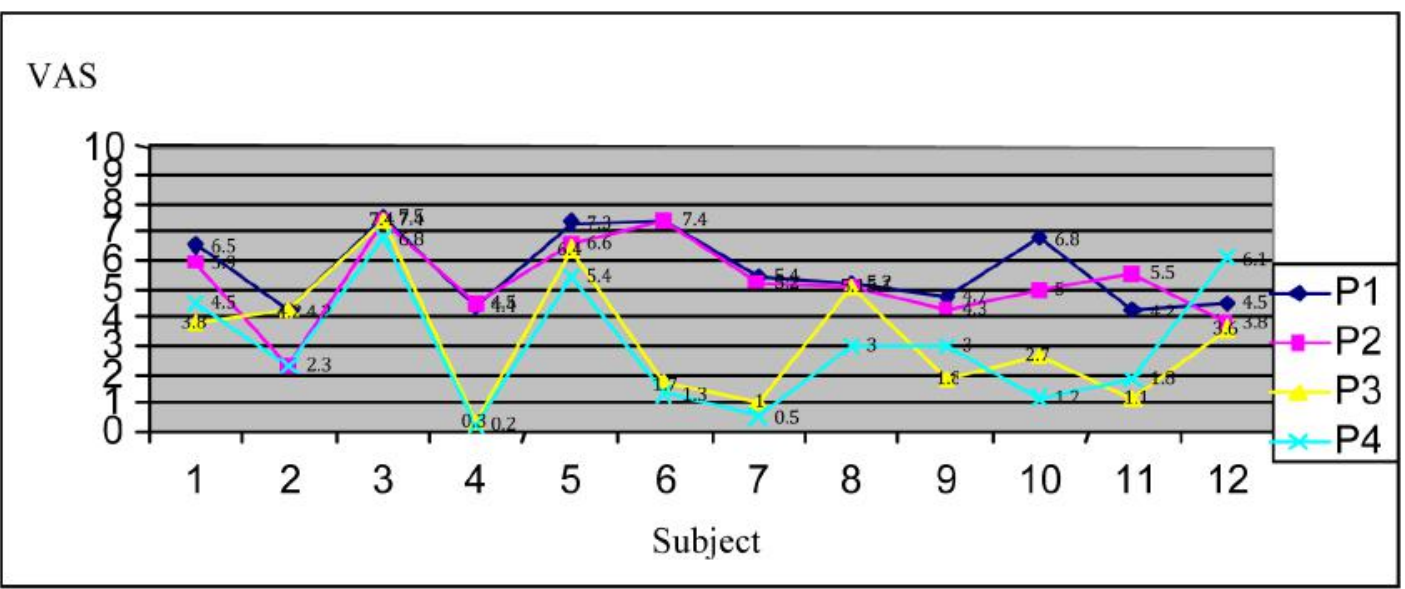

Figure 6. Changes in the Walking Time of Taping and Exercise Group.

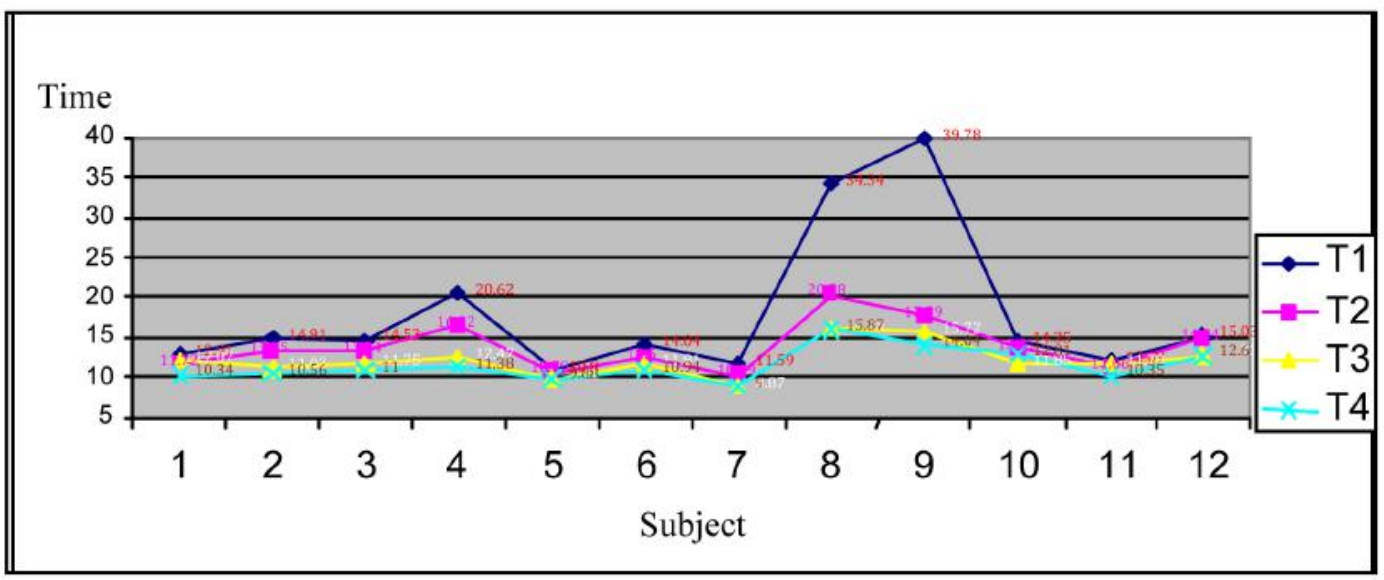

T1 $=$ walking time day 1 ;

T2 = walking time day 2 ;

T3 = walking time at the beginning of week 4; T4 = walking time at the beginning of week 7

T2 was not assessed in the exercise group, assuming that there was no change in the walking time with only one day exercise $(\mathrm{T} 1=\mathrm{T} 2)$. 
Figure 7. Change in the Walking Time of Exercise Group.

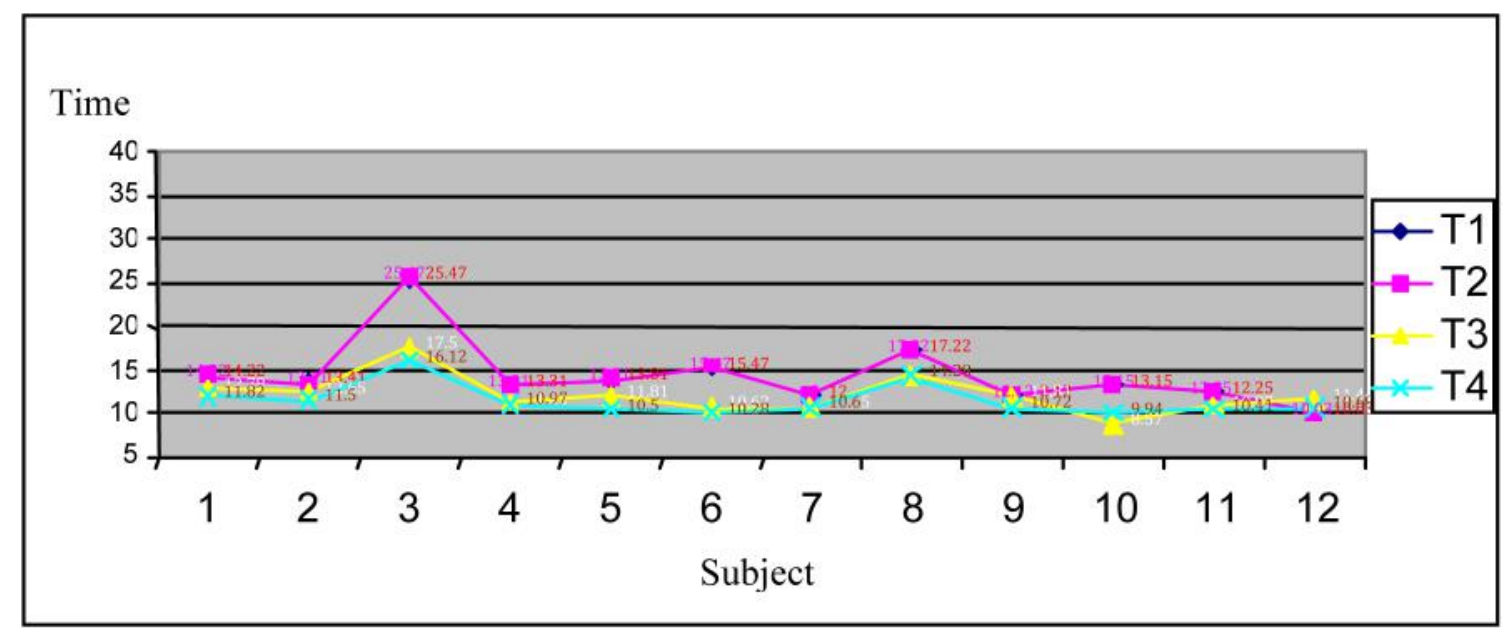

\section{DISCUSSION}

Various studies have been made to prove the efficacy of McConnell's patellar taping for patients with knee osteoarthritis. Results of this study support the use of knee patellar tape to treat moderate pain in patients with knee osteoarthritis. Various studies have also been conducted to demonstrate the effectiveness of exercise in the management of knee pain. Nevertheless, the sensation of pain often restricts the movement of knee osteoarthritis patients during exercise. Taping reduces pain quickly. Several references reported that pain reduction occurred immediately after tape application. ${ }^{14}$ However, pain may remain about an hour after the application. Significant difference is visible on the second day. ${ }^{15,20}$ Minimal reduction in pain of $1.75 \mathrm{~cm}$ on the VAS has been recommended as the minimum clinically important difference in trials of knee osteoarthritis. ${ }^{4}$ On the second day, $50 \%$ of participants of the study group exceeded the number, while in the control group only $17 \%$ of participants. Pain reduction was greater in the study group. At the beginning of week 4 and 7, most comparisons were decreased much larger than the initial value. This suggests that the tape still have effect three weeks after the tape is removed. This support the evidence of another similar study. ${ }^{4}$

Several mechanisms may explain the painrelieving effect. Patellar taping may improve patellar alignment. ${ }^{4}, 20$ Most of participants had hypermobility of patella. The study group showed improvement of pain and activity of daily living greater than the control group. From these facts, we can postulate that tape application would stabilise the position of the patella. This taping application followed the technique of McConnell's medial patellar gliding. Pain reduction was experienced by participants who have patellar glide and tilt, or patellar glide only, however the level of pain reduction was incomparable.

On their study to evaluate the effects of patellar taping on knee joint proprioception, Callaghan et al found that subjects with good proprioception did not benefit from patellar taping. However, in those healthy subjects with poor proprioceptive ability, patellar taping provided proprioceptive enhancement. ${ }^{21}$

On normal subjects, taping decreases their performances. This may be because of a subtle alteration in the extensor mechanism alignment causing it to function lesser than optimal manner. Pain occurrence and inhibitory effects in this case cannot be explained. Nonetheless, it is suggested that taping application may change the lever arm of quadriceps. ${ }^{22}$

The strength of our study is the general applicability of taping technique. Patients with various education background and skill level can be taught to tape their own knee. The results suggest that special training is not required for this intervention to be effective.

The main limitation of our study was the limited time of study and the possible risk of skin reaction that may occur. Further research 
is needed to evaluate the long term effects of knee taping

\section{CONCLUSIONS}

Medial Patellar Taping in addition to isometric and stretching exercise of quadriceps, iliotibial band, hamstrings and gastrocnemius muscles showed significant improvement of disability better than the untapped group. Benefits of Medial Patellar Taping were maintained three weeks after removal.

\section{REFERENCES}

1. Maly MR, Costigan PA, Olney SJ. Role of knee kinematics and kinetics on performance and disability in people with medial compartment knee osteoarthritis. Clinical Biomechanics (Bristol, Avon). 2006 Dec; 21(10):1051-9. doi:10.1016/j. clinbiomech.2006.06.010.

2. Felson DT. Osteoarthritis: new insights. Part 1: The disease and its risk factors. Ann Intern Med.2000;133:635-46.

3. Felson DT. Osteoarthritis: new insights. Part 2: Treatment approaches. Ann Intern Med.2000; 133:726-37.

4. Hinman RS, Crossley KM, McConnell J, Bennell KL. Efficacy of knee tape in the management of osteoarthritis of the knee: blinded randomized controlled trial. BMJ. 2003 Jul 17; 327:135-8. doi:10.1136/ bmj.327.7407.135.

5. Evy. Humaniora, kenali faktor risikonya. Kompas [Internet]. 2005 Des 12 [cited 2005 Dec]; Available from: http://www. kompas.com/kompas-cetak/0512/12/ humaniora.htm

6. Lund H. Knee osteoarthritis and exercise (published lecture notes). IFSP \& FFI symposium- Oslo; lecture given 2005 June 22. available from: http://www. gigtforeningen.dk/C45FEBE1-B0644893-87AB-2794FB6EE217

7. Reyes TM, Reyes OB. The Knee Joint. In: Kinesiology. Manila: U.S.T. Printing Office; 1978. p.139- 51.

8. Cailliet R. Knee Pain and Disability. $11^{\text {th }}$ ed. Philadelphia: F.A Davis Co; 1981. p.1-
61,133-7.

9. Patellofemoral Problems, Patient Education [Internet]. 2006 July 20 [cited 2006 Aug 26]; Available from: URL: http:// www.orthogate.com/patient-education/ knee/Patellofemoral-problems.html

10. Klippel JH, Crofford LJ, Stone JN, Weyand CM. Primer on the Rheumatic Diseases. $12^{\text {th }}$ ed. Atlanta: Arthritis Foundation; 2001. p.285-97, 636-7.

11. Michaeli A. Clinical approach for the selection of taping techniques for knee pain. PhysioForum [Internet]. 2004 March [cited 2006 Aug 26]; Available from: http://www.physiotherapy.co.za/images/ selection $\% 20$ of $\% 20$ taping $\% 20$ tech $\% 20$ article.pdf

12. Aminaka N, Gribble PA. A Systematic Review of the Effects of Therapeutic Taping on Patellofemoral Pain Syndrome. J Athl Train. 2005 Oct-Dec; 40(4): 341351.

13. Section 2, Sports Injury Management. Chapter 7, Protective Taping and Wraps [Internet]. P. 210-44 [cited 2006 Aug 26]; Available from: http:/connection.lww. com/products/anderson-fundamentals/ documents/tapingsupplement.pdf

14. Hinman RS, Crossley KM, McConnell J, and Bennell KL. Does the application of tape influence quadriceps sensorimotor function in knee osteoarthritis? Rheumatology. $2004 ; 43: 331-6$. doi:10.1093/rheumatology/keh033.

15. Cushnaghan J, McCarthy C, Dieppe P. Taping the patella medially: a new treatment for osteoarthritis of the knee joint? BMJ. 1994 March 19;308(6931):753-5.

16. Ng GYF, Cheng JMF. The effects of patellar taping on pain and neuromuscular performance in subjects with patellofemoral pain syndrome. Clin Rehab.2002 Dec;16(8):821-7.doi: 10.1191/0269215502cr563oa.

17. L Timothy. Hughston sports Medicine Foundation. Knee Taping. Available from: URL http://www.hughston.com/ hha/a $13 \quad 4 \quad 5 . h t m$

18. Altman R, Asch E, Bloch D, Bole G, Borenstein D, Brandt K, Christy W, 
Cooke TD. Development of criteria for the classification and reporting of osteoarthritis. Classification of osteoarthritis of the knee. Arthritis Rheum. 1986 Aug; 29(8): 1039-49.

19. Hurley MV, Scott D.L. Improvements in quadriceps sensorimotor function and disability of patients with knee osteoarthritis following a clinically practicable exercise regime. $\mathrm{Br} \mathrm{J}$ Rheumatol. 1998; 37(11): 1181-7.

20. Hinman RS, Bennell KL, Crossley KM, McConnell J. Immediate effects of adhesive tape on pain and disability in individuals with knee OA. Rheumatology. 2003;42:865-9. doi:10.1093/ rheumatology/keg233.

21. Callaghan MJ, Selfe J, Bagley PJ, Oldham. The effect of patellar taping on knee joint proprioception. J Athl Train. 2002 JanMar; 37(1):19-24.

22. Herrington L. The effect of patella taping on quadriceps strength and functional performance in normal subjects. Phys Ther Sport. 2004;5(1):33-6. doi: 10.1016/j. ptsp.2003.09.002. 